PENANGANAN KASUS ANAK USIA DINI DI KELOMPOK BERMAIN

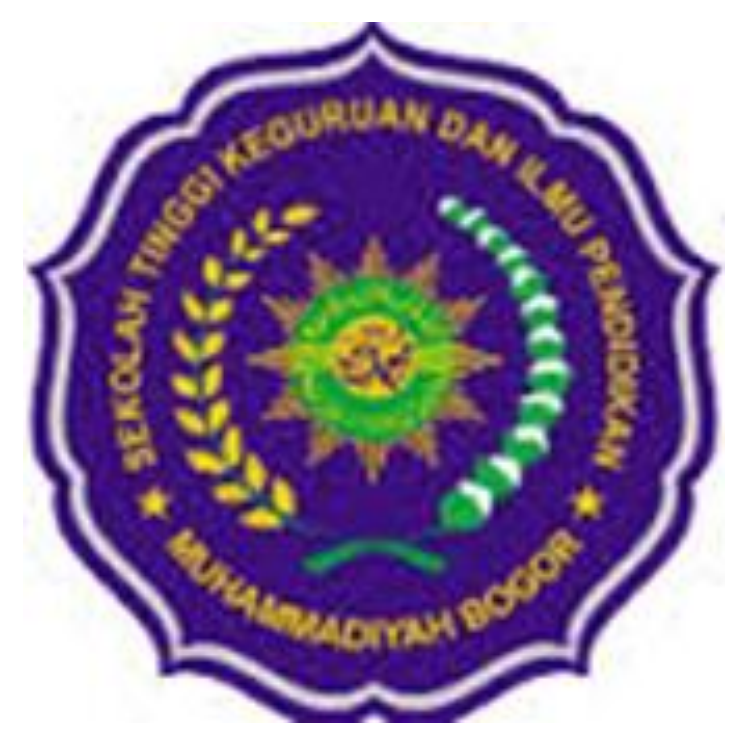

DI SUSUN OLEH:

ENDEN KARTIKA LUCIANA ( NIM : 0142S1D018025 )

NINA UTAMI

(NIM : 0142S1D018026 )

STKIP MUHAMMADIYAH BOGOR

PROGRAM STUDI PENDIDIKAN GURU PAUD

BOGOR 2019 


\section{PENANGANAN KASUS ANAK USIA DINI DI KELOMPOK BERMAIN}

\section{A. Tujuan pembelajaran : Mahasiswa dapat memahami teknik menangani permasalahan AUD di Kelompok Bermain}

\section{B. Materi Pembelajaran}

\section{Pengertian Kelompok Bermain}

Kelompok Bermain (KB) adalah wadah pembinaan sebagai usaha kesejahteraan anak dengan mengutamakan kegiatan bermain dan menyelenggarakan pendidikan prasekolah bagi anak berusia sekurangkurangnya 3 tahun sampai dengan memasuki pendidikan dasar (Direktorat PAUD, 2006).

Kelompok bermain adalah salah satu bentuk pendidikan anak usia dini pada jalur pendidikan nonformal (PAUD non-formal) yang menyelenggarakan program pendidikan sekaligus program kesejahteraan bagi anak sejak lahir sampai dengan 6 tahun (dengan prioritas anak usia 2 sampai 4 tahun). Kelompok bermain dalam menyelenggarakan pendidikan memfokuskan pada peletakan dasar pengembangan multipotensi dan multi kecerdasan pada diri setiap anak berupa pengetahuan, keterampilan dan sikap sebelum anak memasuki jenjang pendidikan selanjutnya.

2. Karakteristik anak usia dini di kelompok bermain.

Secara umum karakteristik anak usia KB ditandai dengan beberapa periode atau masa yang secara langsung atau tidak langsung mempengaruhi bagaimana seharusnya seorang pendidik menghadapi anak usia dini. Masa masa tersebut diantaranya masa peka, egosentrisme, meniru, berkelompok, masa bereksplorasi dan pembangkangan (Asmawati, Luluk. (2017). Pengelolaan kegiatan pengembangan Anak Usia Dini. Tanggerang Selatan: Universitas Terbuka). 


\section{Permasalahan Anak Usia Dini Di Kelompok Bermain}

Setiap anak memiliki karakteristik perkembangan yang berbeda-beda. Untuk memahami bagaimana perkembangan anak, juga perlu dipahami permasalahan-permasalahan apa yang dialami anak selama perkembangannya. Hal ini perlu di lakukan agar pendidik benar-benar dapat mengetahui setiap perubahan yang terjadi pada diri anak. Berbagai bentuk perilaku anak seperti anak agresif, tak bisa tenang dan suka bertengkar, anak yang sulit berbicara, ketakutan bertemu orang asing, atau sering menangis bila ditinggal ibunya pergi merupakan tanda bahwa mereka sedang menghadapi masalah. Permasalahan yang dihadapi anak dapat dilihat melalui tingkah laku yang ditunjukkan anak maupun keluhankeluhan yang disampaikan oleh orang-orang sekitar anak.

Adapun permasalahan atau kasus anak usia dini biasanya terlihat ketika seorang anak mengalami kesulitan dalam belajar. Undang - undang menyatakan bahwa jika seorang anak memiliki kesulitan yang secara signifikan lebih besar dari anak-anak lain seusianya dalam menyelesaikan pekerjaan sekolah, juga dalam berkomunikasi atau berprilaku, mereka di katakan memiliki kesulitan dalam belajar (Thomson, jenny(2010). Memahami anak berkebutuhan khusus. Erlangga)

Berikut beberapa permasalahan perilaku anak usia dini di Kelompok Bermain dan penanganannya yaitu :

a. Agresif, yaitu tingkah laku menyerang baik secara fisik maupun verbal atau melakukan ancaman sebagai pernyataan adanya rasa permusuhan. Perilaku tersebut cenderung melukai anak lain, seperti mencakar, menggigit dan memukul. Solusi permasalahannya yaitu, tetap tenang untuk memberikan contoh kepada anak agar mengendalikan emosinya.

b. Penakut/ phobia, merupakan munculnya rasa takut yang berlebihan akibat suatu trauma atau peristiwa yang membekas di benaknya dan mempengaruhi jiwanya. 
Solusi permasalahannya yaitu,

1) Kenalkan anak pada sumber rasa takutnya.

2) Latih anak untuk mengatasi rasa takutnya.

3) Berikan dukungan penuh atas setiap usaha yang dilakukan anak.

4) Ciptakan kondisi nyaman pada anak.

5) Jangan menertawakan anak

c. Hiperaktif yaitu Suatu kondisi yang menunjukan pada ketidak mampuan untuk mengontrol perilakunya sehingga aktivitasnya melebihi rata-rata anak pada umumnya. Sebagai contoh tingkah laku seperti mengetuk-ngetuk tangan/ kaki dan sulit duduk diam lebih dari beberapa detik.

Solusi permasalahnnya yaitu,

1) Tunjukan sikap tegas tapi tak perlu marah

2) Konsisten terhadap apa yang pernah di janjikan atau di ucapkan.

3) Mencari tahu penyebab perilaku anak aktif.

d. Gagap/ kesulitan berkomunikasi yaitu kondisi di mana penderitanya mengalami gangguan dalam berbicara penderita gagap biasanya mengulang suku kata atau memperpanjang penyebutan suatu kata ketika berbicara.

Solusi permasalahan yang di lakukan oleh pendidik, yaitu:

1) Terapi bicara dengan membacakan buku cerita agar kosa katanya bertambah.

2) Dengarkan apa yang anak sampaikan. Lakukan kontak mata secara alami dengan anak selagi berbicara.

3) Berbicara secara perlahan. Anak gagap secara tidak sadar akan mengikuti kecepatan berbicara temannya bicaranya, jika temannya berbicara secara perlahan, anak gagap juga 
akan berbicara secara perlahan, sehingga dapat lebih lancar menyampaikan maksudnya.

e. Tantrum yaitu ledakan emosi biasanya dikaitkan dengan anak-anak dalam kesulitan emosional, ditandai dengan sikap keras kepala, menangis, menjerit, berteriak, menjerit-jerit, pembangkangan, mengomel marah.

Solusi permasalahan yang dilakukan oleh pendidik yaitu,

1) Mencari tahu apa penyebab yang membuat anak seperti itu.

2) Pendidik harus tetap tenang dan tidak emosi jika anak tengah mengalami tantrum.

3) Carilah pengalihan biasanya anak sangat mudah melupakan melupakan sesuatu dan tertarik pada hal baru.

f. Pemalu adalah reaksi emosional yang tidak menyenangkan, yang timbul pada seseorang akibatnya memiliki penilaian negatif terhadap dirinya. Cara menanganinya yaitu:

1) Melibatkan anak pada kegiatan yang menyenangkan

2) Belajar bergabung melalui permainan

3) Mengajarkan cara mulai berteman

4) Dorong anak berpartisipasi dalam kelompok

g. Negativisme (pembangkangan) yaitu reaksi anak berupa pelanggaran terhadap peraturan-peraturan yang ada. Cara menanganinya yaitu:

1) Menegur dengan penuh kasih sayang apabila anak dalam kondisi membangkang

2) Sebaiknya anak diberi waktu untuk pendinginan (cooling down)

3) Pemberian nasihat. 
4. Teknik Penanganan Permasalahan Anak Usia Dini Di Kelompok Bermain

Pada hakikatnya, tidak ada satupun teknik yang efektif untuk menangani permasalahan anak yang berbeda-beda. Penggunaan suatu teknik akan bergantung kepada karakteristik anak, jenis permasalahan, kemampuan serta keterampilan pemberi bantuan. Di antara berbagai teknik yang dapat dilakukan orangtua dan pendidik untuk membantu menangani permasalahan anak adalah sebagai berikut :

a. Latihan

Dengan latihan kita dapat mengetahui dan mengevaluasi sejauh mana, juga dapat mengetahui di mana kelemahan anak. Latihan di berikan kepada anak untuk melatih konsentrasi atau aspek kognitif anak.

b. Permainan

Permainan dan bermain merupakan kebutuhan bagi anak. Melalui permainan anak dapat mengembangkan berbagai aspek. Termasuk aspek sosial emosional yang dapat membantu pengembangan karakter anak usia dini. Permainan merupakan sumber media untuk menstimulasi anak.

c. Saran dan nasihat

Dalam menangani masalah anak saran dan nasehat sangat di perlukan untuk mengarahkan anak dan menjelaskan nilai baik buruk kepada anak. Ketika kita memberikan nasihat akan mudah di terima ketika anak masih berada pada usia dini.

d. Pengondisian

Ketika kita akan mengatasi masalah yang sedang di hadapi anak hendaknya kita harus melihat kondisi dan keadaan yang memungkinkan untuk melakukannya.

e. Model dan peniruan 
Anak adalah peniru ulung, anak hanya melakukan apa yang ia lihat, ia dengar dan ia rasakan maka dari itu kita sebagai sebagai orangtua harus menjadi teladan yang baik bagi anak.

\section{f. Konseling}

Merupakan proses yang terjadi antara anak dan seorang konselor yang membantu anak-anak untuk sembuh dan kembali rasa percaya dirinya. Selama konseling, seorang anak didorong untuk dapat menyatakan perasaan mereka.

\section{KESIMPULAN}

Anak usia dini dikelompok bermain pada umumnya memiliki karakteristik yang unik dan istimewa. Karakteristik itu ditandai dengan beberapa periode/ masa yang secara langsung maupun tidak langsung mempengaruhi cara seorang pendidik menghadapi anak usia dini. Masamasa itu diantaranya masa peka, egosentris, meniru, berkelompok, bereksplorasi. Dalam menghadapi masa-masa tersebut sorang pendidik harus bersikap bijak dan memahami karakteristik anak, sehingga perkembangan anak dapat tercapai sesuai dengan tujuan.

Dalam diri individu anak sering kali terdapat beberapa kendala atau permasalahan yang mempengaruhi proses anak dalam belajar. Adapun permasalah yang biasanya muncul dari diri anak seperti, perilaku agresif, tantrum, penakut/ phobia, hiperaktif, dan kesulitan berkomunikasi. Pendidik dan orangtua harus menangani konflik/ permasalahan tersebut agar tidak berlarut-larut demi kehidupan anak dimasa yang akan datang. Teknik penanganan masalah yang dapat dilakukan oleh pendidik, yaitu dengan latihan, permainan, saran dan nasihat, pengondisian, model dan peniruan, dan konseling. 


\section{Soal Pilihan Ganda}

1. Perilaku yang di tunjukan anak yang seringkali ingin mengambil apa saja yang dilihatnya dan menarik perhatiannya merupakan karakteristik anak
a. Selalu ingin tahu
b. Agresif
c. Unik
d. Egosentris

2. Berikut ini yang merupakan aspek perkembangan anak yang di prioritaskan dalam kelompok bermain, kecuali.
a. Kecerdasan emosi
b. Kecerdasan sosial emosional
c. Kecerdasan bahasa
d. Cita-cita

3. Kelompok bermain memberikan kesempatan untuk belajar melalui bermain pada anak usia.
a. 2 - 4 tahun
b. 2 - 3 tahun
c. 3 - 4 tahun
d. 3 - 6 tahun

4. Berikut ini merupakan permasalahan yang muncul pada anak usia dini, kecuali................
a. Tantrum
b. Agresif
c. pendiam
d. Anak sehat 
5. Anak yang sulit duduk diam lebih dari beberapa detik menunjukan tanda-tanda
a. Pemalas
b. Hiperaktif
c. Emosi
d. Periang

6. Perilaku yang cenderung melukai anak lain seperti mencakar atau memukul di sebut
a. Humoris
b. Pemarah
c. Agresif
d. Emosional

7. Di bawah ini hal yang dapat dilakukan oleh pendidik dalam menghadapi anak agresif adalah ...........
a. Perbanyak kegiatan yang menggunakan gerakan motorik
b. Menjauhi anak
c. Memisahkan anak dari temannya
d. Mendongeng

8. Penanganan permasalahan anak usia dini merupakan tugas dari
a. Orang tua
b. Guru dan orangtua
c. Anak itu sendiri
d. Semua benar

9. Teknik penanganan permasalahan anak usia dini dapat di lakukan dengan
a. Observasi 

b. Rekreasi
c. Interaksi
d. Permainan

10. Berikut ini adalah salah satu cara mengatasi permasalahan AUD, yaitu
a. Memberi hukuman fisik
b. Pemberian motivasi positif terhadap anak
c. Mengabaikan anak yang bermasalah
d. Mencatat anak yang absen

\section{E. Soal Essay}

1. Apa pengertian dari kelompok bermain ?

2. Aspek apa saja yang di kembangkan di kelompok bermain ?

3. Sebutkan permasalahan perilaku yang biasanya muncul pada anak di kelompok bermain yang kamu ketahui ?

4. Sebutkan solusi permasalahan yang dapat dilakukan pendidik dalam menghadapi anak yang mengalami kesulitan berkomunikasi?

5. Sebutkan teknik penanganan permasalahan anak usia dini ? 


\section{Kunci jawaban pilihan ganda}

1. a. Selalu ingin tahu

2. d. Cita-cita

3. a. 2-4 tahun

4. d. Anak sehat

5. b. Hiperaktif

6. c. Agresif

7. a. Perbanyak kegiatan yang menggunakan gerakan motorik

8. b. Guru dan orangtua

9. d. Permainan

10. b. Pemberian motivasi positif terhadap anak

\section{Kunci jawaban Essay}

1. Kelompok bermain adalah salah satu bentuk paud pada jalur pendidikan non formal yang menyelenggarakan program pendidikan sekaligus program kesejahteraan bagi anak usia 2 - 4 tahun.

2. Aspek nilai agama dan moral, aspek fisik motorik, aspek kognitif, aspek sosial emosional, aspek bahasa, aspek seni.

3. permasalahan perilaku yang umumnya muncul pada anak, yaitu

- agresif

- penakut/ phobia

- hiperaktif

- gagap/ kesulitan berkomunikasi

- tantrum

4. Solusi permasalahan yang di lakukan oleh pendidik dalam menangani permasalahan dalam berkomunikasi, yaitu:

a. Terapi bicara dengan membacakan buku cerita agar kosa katanya bertambah,

b. Dengarkan apa yang anak sampaikan . Lakukan kontak mata secara alami dengan anak selagi berbicara. 
c. Berbicara secara perlahan. Anak gagap secara tidak sadar akan mengikuti kecepatan berbicara temannya bicaranya, jika temannya berbicara secara perlahan,anak gagap juga akan berbicara secara perlahan,sehingga dapat lebih lancar menyampaikan maksudnya.

5. teknik penanganan permasalahan anak usia dini,yaitu:
a. latihan
b. permainan
c. saran dan nasihat
d. pengondisian (conditioning)
e. model dan peniruan
f. konseling 


\section{DAFTAR PUSTAKA}

Asmawati, luluk.(2017).Pengelolaan kegiatan pengembangan anak usia dini. Tanggerang selatan:Universitas Terbuka

Arsyad, Arsyad, \& Sulfemi, Wahyu Bagja. (2016). Pengembangan Keprofesian Berkelanjutan (PKB) Bagi Guru Melalui Program Induksi Guru Pemula (PIGP). Seminar Nasional STKIP Muhammadiyah Bogor.2 (2), 12-22.

Arsyad, Arsyad, \& Sulfemi, Wahyu Bagja. (2013). Pengaruh Persepsi Guru Tentang Kemampuan Manajerial Kepala Sekolah dan Kecerdasan Emosional Guru Terhadap Kinerja Guru (Studi Kasus Di SMK Muhammadiyah 6 Kabupaten Bogor). Fascho 2 (1), 1-9

Depdiknas, 2009. Permendiknas No. 58 tahun 2009 tentang standar pendidikan Anak Usia Dini. Jakarta:2009.

Sultoni, Wahyu Bagja, (2007). Ilmu Sosial Dasar. Bogor : STKIP Muhammadiyah.

Sudirman, Sudirman \& Sulfemi, Wahyu Bagja. (2010). Korelasi Antara Konsep Diri Guru dengan Profesionalisme Guru di SMA Negeri 1 Pamijahan Kabupaten Bogor. Edutecno 2 (2), 10-19.

Sugiri, Sugiri \& Sulfemi, Wahyu Bagja. (2011). Pendidikan Multi Kultur di Sekolah Berbasis Keagamaan. Edutecno. 3 (2), 11-20

Sulfemi, Wahyu Bagja. (2016). Kompetensi Profesionalisme Guru Indonesia dalam Menghadapi MEA. Prosiding Seminar Nasional STKIP Muhammadiyah Bogor. 1 (1), 62-77.

Sulfemi, Wahyu Bagja. (2016). Perundang-Undangan Pendidikan. Bogor : Program Studi Administrasi Pendidikan STKIP Muhammadiyah Bogor.

Sulfemi, Wahyu Bagja. (2016). Modul Pembelajaran Ilmu Sosial dan Budaya Dasar. Bogor : STKIP Muhammadiyah Bogor.

Sulfemi, Wahyu Bagja. (2018). Manajemen Kurikulum di Sekolah. Bogor : Visi Nusantara Maju.

Sulfemi, Wahyu Bagja dan Desmiati, Zulaicha. (2018). Model Pembelajaran Missouri Mathematics Project Berbantu Media Relief Experience dalam Meningkatkan Hasil Belajar Siswa. Jurnal Pendas Mahakam . 3 (3), 232245.

Sulfemi, Wahyu Bagja. (2019). Asosiatif Layanan Tenaga Perpustakaan Sekolah Dengan Motivasi Membaca Siswa di Kabupaten Bogor. Edutecno. 19 (2), $1-10$.

Sulfemi, Wahyu Bagja. (2019). Manajemen Pendidikan Berbasis Multi Budaya. Bogor : STKIP Muhammadiyah Bogor 
Sulfemi, Wahyu Bagja dan Mayasari, Nova. (2019). Peranan Model Pembelajaran Value Clarification Technique Berbantuan Media Audio Visual Untuk Meningkatkan Hasil Belajar IPS. Jurnal Pendidikan. 20. (1). 53-68.

Sulfemi, Wahyu Bagja (2019). Model Pembelajaran Kooperatif Mind Mapping Berbantu Audio Visual Dalam Meningkatkan Minat, Motivasi dan Hasil Belajar IPS. Jurnal Pendidikan Ilmu Pengetahuan Sosial Indonesia (PIPSI). 4 (1), $13-19$.

Sulfemi, Wahyu Bagja., \& Yuliana, Desi. (2019). Penerapan Model Pembelajaran Discovery Learning Meningkatkan Motivasi dan Hasil Belajar Pendidikan Kewarganegaraan. Jurnal Rontal Keilmuan Pancasila dan Kewarganegaraan 5 (1), 17-30

Yusfiriadi, Yusfiriadi, \& Sulfemi, Wahyu Bagja. (2011). Pemberdayaan Unit Produksi Melalui Pendekatan Manajemen Stratejik di SMK Pertiwi Kabupaten Bogor. Edutecno 3 (1), 1-10

Yusfiriadi, Yusfiriadi, \& Sulfemi, Wahyu Bagja. (2012). Penyelewangan Dana Dalam Dunia Pendidikan. Fascho 1 (1), 1-9.

Thomson, jenny (2010). Memahami anak berkebutuhan khusus. Erlangga http://alloh maha besar 88.wordpress.com/2015/02/06/permasalahan-anak-usiadini 